\title{
EPC global Network 표준을 따르는 RFID 교육용 시스템의 구현 Implementation of a System for RFID Education to be based on an EPC global Network Standard
}

\author{
김대희", 정중수, 김휴찬*, 정광욱**, 김석규, \\ 안동대학교 정보통신공학과*, 제주한라대학 전자상거래과**, 구미 1 대학 정보통신공학과*** \\ Dae-Hee Kim(eogml119@hotmail.com) ${ }^{*}$, Joong-Soo Chung(jschung@andong.ac.kr) ${ }^{*}$, \\ Hyu-Chan Kim(khc@hc.ac.kr) ${ }^{* *}$, Kwang-Wook Jung(kwjung@kumi.ac.kr) ${ }^{* * *}$, \\ Seog-Gyu Kim(sgkion@andong.ac.kr)
}

\section{요약}

본 논문에서는 $\mathrm{RFID}$ 기술 중 리더와 능동형 태그간 $900 \mathrm{MHz}$ 대역을 사용하여 $\mathrm{RFID} \mathrm{EPC} \mathrm{global}$ network 교육용 시스템을 구현하였다. 능동형 태그와 리더의 설계를 임베디드 환경에서 제시하였으며 리더 와 접속 가능한 서버의 소프트웨어 개발은 $\mathrm{PC}$ 원도우 운영체제 환경에서 실현하였다. 개발 환경으로는 리 더와 태그의 프로세서로 ATmegal28를 사용하였고, 개발 언어는 C 언어로, 이를 제어하기 위하여 AVR 컴파일러가 사용되었다. 서버인 $\mathrm{PC}$ 에서는 비주얼 스튜디오상의 비주얼 $\mathrm{C}++$ 언어가 사용되었다. 시스템은 $\mathrm{PC}$ 에서는 리더를 통해 $\mathrm{EPC}$ global 데이터가 포함되어 있는 태그를 붙여 관리하고, 인터넷을 통해 태그에 대한 정보 획득, 태그 메모리에 데이터를 읽기/쓰기 기능을 가지고 있다. 마지막으로 태그 메모리에 기록된 데이터를 리더를 통해 PC에 전송하고 읽기 명령으로 수신된 데이터와 태그로 전송하고 읽기 명령으로 수신 된 데이터와 태그로 전송한 데이터를 비교한다. 이러한 기능을 가진 $900 \mathrm{MHz}$ 대역의 $\mathrm{EPC}$ global Network $\mathrm{RFD}$ 교육용 시스템을 구현하였다.

- 중심어 : | RFID 시스템 | 리더 | 능동형 태그 |

\section{Abstract}

This paper presents the implementation of RFID EPC global network educational system based on using $900 \mathrm{MHz}$ air interface between the reader and the active tag. The software of reader and the active tag is developed on embedded environment, and the software of PC controlling the reader is based on window OS operated as the server. The ATmegal28 VLSI chip is used for the processor of the reader and the active tag. As the development environment, AVR compiler is used for the reader and the active tag of which the programming language is $\mathrm{C}$. The visual $\mathrm{C}++$ language of the visual studio on the $\mathrm{PC}$ activated as the server is used for development language. Main functions of this system are to control tag containing EPC global Data by PC through the reader, to obtain information of tag through the internet and to $\mathrm{read} /$ write data on tag memory. Finally the data written from the active tag's memory is sent to the PC via the reader as "read" operation and compare the received data with one already sent to the tag. Software implementation of $900 \mathrm{MHz}$ EPC global RFID educational system is done on the basis of these functions.

Keyword : | RFID System | Raeder | Active Tag |

접수번호 : \#090707-001

접수일자 : 2009년 07월 07일
심사완료일 : 2009년 09월 10일

교신저자 : 김대회, e-mail : eogml119@hotmail.com 


\section{I. 서 론}

오늘날 유비쿼터스 시대에 가장 많이 활용될 RFID 기술의 급속한 발달과 더불어 수많은 응용 서비스들이 사용되고 있으며, 향후에도 더욱더 다양한 서비스가 요 구된다[1][2]. 특하 반도체 기술의 발전과 인터넷의 등 장으로 유통, 물류, 의료, 교육 등 다양한 분야에 적용되 고 있다. 2003년 월마트가 파렛, 케이스에 태그를 부착 하는 RFID 의무화를 발표하면서 기술 개발, 표준화, 시 범사업 등이 촉진되어 왔으며, 파렛 단위의 태그 식별 기술은 성숙단계에 이르러 물품단위에 태그를 부착함 에 따라 태그를 포함한 개별 물품 식별 RFID 시장이 2008년 251억 달러에서 2018년도에는 약 8,263억 달러 에 달할 것으로 전망되고 있다[3]. EPC global을 중심으 로 개별 물품 식별에 가장 적합한 주파수 선택을 위한 시험이 저주파, 고주파, 초고주파 대역에서 의류, 의약 품, DVD 인식 등 7가지 시나리오에서 진행 중이며 다 양한 형태의 RFID 기술 등에 대한 연구도 이루어지고 있다[4]. 하지만 RFID 기술 교육에 필요한 장비들은 부 족한 실정이다. UHF 대역에서의 리더와 태그 간의 통 신 프로토콜인 EPC global의 Class-1 Gen-2 규격이 ISO/IEC 18000-6 Type A ,Type B이어, $900 \mathrm{MHz}$ 대역 의 국제 단일 표준인 18000-6 type C로 2006년 6월에 확정되었다[5]. Class-1 Gen-2 규격은 기존 $\mathrm{EPC}$ $\mathrm{CO}$ (class 0), C1(class 1) 및 ISO 1800-6 Type A, B에 비해 높은 인식속도와 동시에 유연한 태그 식별 프로토 콜, 보안 기능의 강화 등 다양한 측면에서 기술적 우워 를 갖는다. 현재 $900 \mathrm{MHz}$ 대역의 $\mathrm{RFID}$ 리더 장비는 Alien 사의 ALR-9800, ALR-9900[6], AWID 사의 MPR-3014[7]등 다수 있으나 이들의 목적은 테모용으 로, 기술 교육은 매우 미흡하다. 또한 국내의 경우에 하 이버스 사의 RS-232, RS-422 인터페이스를 기반으로 하는 RFID Study Kit KIS-KIT1000U 기술 교육용 $\mathrm{RFID}$.장비[8] 정도가 있다. 또한 수동형 $\mathrm{RFID}$ 태그[9] 등은 Hitachi, Alien, Impinj, Philips 등에서 EPC global Class-1 Gen-2 규격을 따르는 매우 많이 출시하였고, ISO 18000-6 type C가 제정됨으로써 Impinj와 Philips 를 비롯한 여러 메이저 업체들에서 상호 호환성이 검증
된 대량의 칩 생산이 이루어지고 있으며. 능동형 RFID 태그도 Savi, e-Logicity, AllSet, Hi-G-Tek와 국내 기 업들에서도 제작되고 있으나[4] 기술 교육을 위한 능동 형 태그는 전무한 실정이다.

따라서 본 논문에서는 $900 \mathrm{MHz}$ 대역의 $\mathrm{EPC}$ global 표준인 18000-6 Type C 규격(이 규격을 이후 "EPC global 규격”으로 표기함)을 만족하는 능동형 태그(이 후 “태그"로 표기함)와 리더를 교육용으로 활용 가능하 도록 임베디드 하드웨어상에 구현하였다. 이전에 연구 된 교육용 장비[2]와 하이버스사의 교육용 장비[8]과 보 다 다음과 같은 성능 향상이 이루어 졌다. 본 논문에서 제안한 $\mathrm{RFID}$ 교육용 시스템은 $\mathrm{EPC}$ global 표준을 따 르고 실제 시스템 운영환경과 같은 EPC Air Interface 규격을 만족하고, 리더와 서버 PC간에 RS-232-C 접속 을 통하여 리더를 제어하였던 것을 인터넷(TCP/IP)접 속을 지원하도록 하였으며, $\mathrm{EPC}$ 코드중 하나인 SGTIN-96을 적용하여 구현되어 앞으로 개별 물품 식 별 RFID 시장의 활성화를 대비하기 위한 기술 교육용 시스템을 구현하였다. 임베디드 하드웨어 구성 시 $900 \mathrm{MHz} z$ 무선대역(이후 "대역"으로 표기함)의 $\mathrm{RFD}$ 전 용 VLSI 칩을 사용하였고, 하드웨어 접속부는 디스크 리트(discrete) 소자를 활용하여 $900 \mathrm{MHz}$ 대역은 만족 하고 전기적 통신에 근거한 통신방식은 EPC global 규 격을 만족한다. 아울러 리더에 접속되어 이를 제어하는 서버의 $\mathrm{PC}$ 소프트웨어 개발을 윈도우 환경에서 비쥬얼 $\mathrm{C}++$ 언어를 사용하였다.

본 논문의 구성은 2장에서 $\mathrm{RFID} \mathrm{EPC} \mathrm{global}$ Network 교육용 시스템의 구조에 대하여 설명하였다. 3 장에서는 본 논문에서 제안한 시스템의 태그와 리더 의 설계 개념, 리더를 통한 서버와 태그 간의 프로토콜 흐름도, 서버의 소프트웨어 구조, 데모 프로그램의 설 계, 템플릿의 설계, 리더와 능동형 태그의 소프트웨어 구조등을 설명하였다. 4장에서는 제안한 시스템을 실제 환경에서 추진한 기능 점검에 대하여 기술하였다. 마지 막으로 5 장에서는 본 연구의 결론과 향후 연구 방향에 대하여 간략히 기술하였다. 
II. RFID EPC global Network 교육용 시스 템의 구조

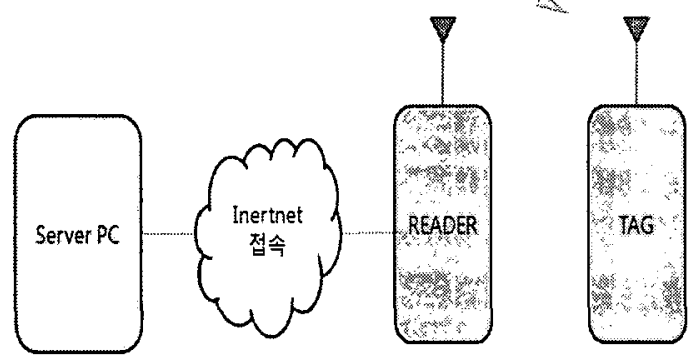

그림 1. RFID EPC global Network교육용 시스템

본 논문에서 제안된 $900 \mathrm{MH} z$ 대역의 $\mathrm{RFID} \mathrm{EPC}$ global Network 교육용 시스탬에 활용되는 리더 및 태 그, 리더와 접속되는 서버의 시스템 구성형태는 [그림 1]과 같다. 서버로 할용되는 $\mathrm{PC}$ 와는 리더와 인터넷 (TCP/IP기반)으로 접속되며, 리더는 서버의 제어를 받 아 동작한다. 리더와 태그 사이에는 RFID 전용 VLSI 칩을 사용하여 $900 \mathrm{MHz}$ 대역을 만족하고, 하드웨어 통 신 기반은 EPC global 규격을 준수하여 통신하도록 하 였다. 따라서 리더와 서버 사이에는 EPC global 규격의 패킷을 그대로 활용하도록 하였다. 서버는 비주얼 C 언 어를 활용하는 윈도우 환경에서 동작되며, 리더와 태그 의 하드웨어 구조는 매우 윳사하며, 프로세서는 ATmega128를 사용하였고, 이를 제어하기 위하여 AVR 컴파일러를 사용하였다. 따라서 시스템의 구동은 $\mathrm{PC}$ 의 동작으로 리더와 인터넷으로 접속하고, 리더와 태그는 EPC global Data를 넣은 RFID 명령어 패킷을 송신하며, 그 응답 패킷을 역시 리더를 통해 수신 할 수 있도록 하였다.

\section{III. 주요 설계 및 구현}

\section{1. 설계 개념}

본 논문에서 구현한 시스템은 크게 하드웨어와 소프 트웨어 부분으로 나눌 수 있다. 하드웨어는
ATmegal28을 사용하여 주변 희로를 구성하였다. $900 \mathrm{MHz}$ 대역의 RFID 전용 VLSI 칩을 활용하여 대역 은 $900 \mathrm{MHz}$ 를 만족하고, 하드웨어 관련 통신 기반은 $\mathrm{EPC}$ global 규격을 만족하도록 구현하였다. 소프트웨 어는 전적으로 $\mathrm{EPC}$ global 규격을 만족하도록 구현하 여 교육용도로 활용하도록 하였다. 본 논문에서 구현된 $\mathrm{RFID}$ 장비의 하드웨어 구조를 살펴보면, 리더와 태그 가 $900 \mathrm{MHz}$ 대역 접속부는 기본적으로 동일하나 인터 페이스부가 다르다. 태그는 [그림 2]와 같이 리더에서 전송되는 데이터 또는 식별코드와 같은 데이터를 송수 신하는 트랜시버와 식별코드나 사용자가 입력한 정보 를 저장하는 메모리 및 마이크로컨트롤러가 포함된 IC 로 구성되어 있다. 리더는 서버와 접속을 위해 [그림 3] 과 같이 인터넷(TCP/IP기반) 접속을 포함한다. 내부 구 조는 태그와 통신을 수행하는 트랜시버와 서버의 제어 명령에 따라 처리하는 ATmega128 프로세서 및 응용 서버 컴퓨터와 통신 하는 이더넷 접속부, 리더의 동작 상태를 간략하게 사용자에게 시각적으로 보여주기 위 한 모니터, 정보를 저장하는 메모리가 포함된 IC로 구 성되어 있다.

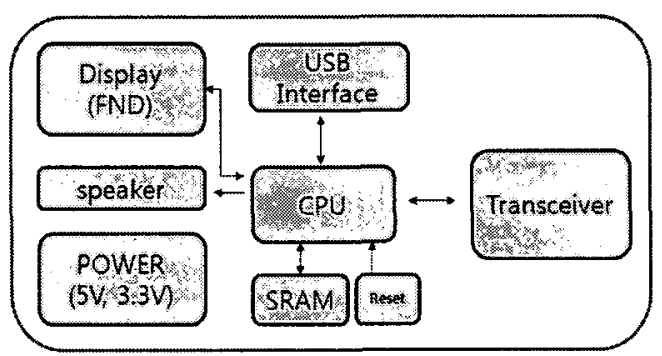

그림 2. RFID 교육용 시스템 태그 구조

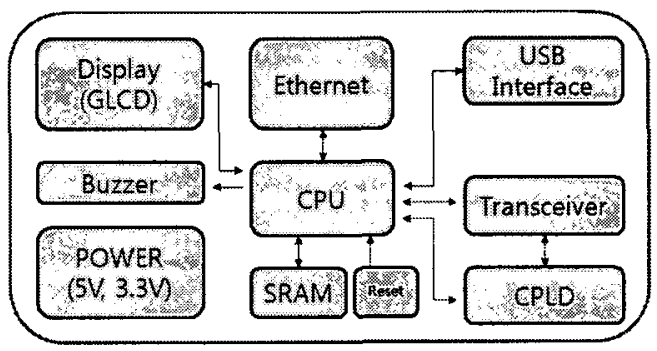

그림 3. RFID 교육용 시스템 리더 구조 


\section{2. 프로토콜 흐름도}

본 시스템에서 리더와 태그의 원활한 정보전달을 위 해서는 우선 리더는 다수의 태그 중 통신 가능한 태그 를 선별하고, 이후 선별된 태그와 정보전달을 수행한다. 이때 리더는 태그로 Command(명령) 패킷을 전달하고, 그에 대한 응답으로 태그는 리더에게 Response(응답) 패킷을 전달한다. EPC global network 규격에 따라, 리 더를 통한 서버와 태그 간에 프로토콜 흐름도의 전반적 인 처리과정은 [그림 4]와 같다. 이때 리더와 서버는 인 터넷으로 접속되어 미들웨어 처리과정중 태그에 $\mathrm{EPC}$ 데이터의 기록 및 읽기 과정을 수행하고, 리더와 태그 는 $900 \mathrm{MHz}$ 무선으로 접속되며 RFID 시스템에서 서버 의 태그 인식, 태그에 정보의 쓰기 및 읽기 과정을 수행 한다. 리더와 서버는 인터넷으로 접속하며 이 과정은 $\mathrm{TCP} / \mathrm{PP}$ 소켓 구동으로 처리되며, 리더의 전원 구동 시 서버로 TCP/IP 프로토콜을 구동시키는 서버개념으로 처리하고, 서버는 TCP/IP 소켓의 들기(listen처리)로 클라이언트 개념으로 처리한다. [그림 4]의 프로토콜 흐 름은 아래와 같이 8단계로 이루어졌다.

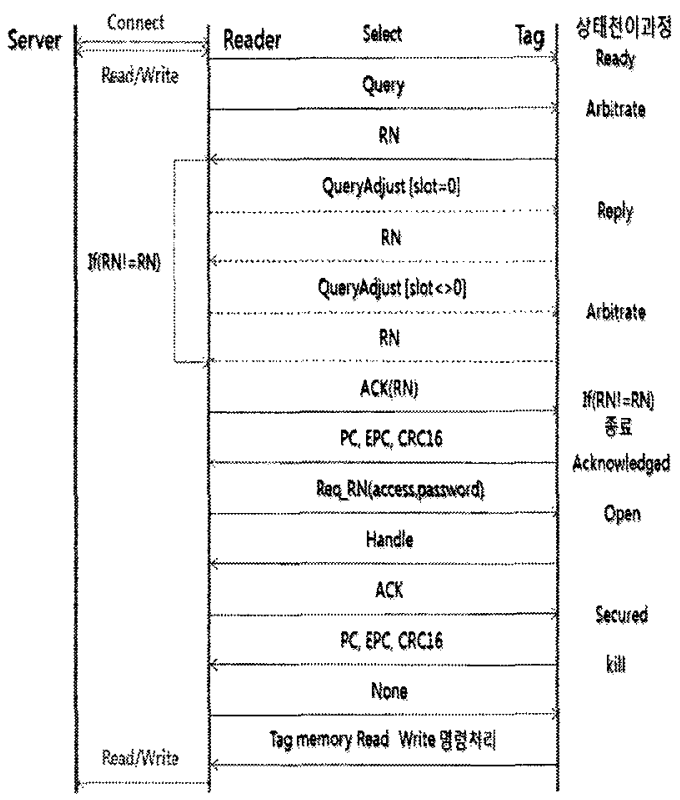

그림 4. RFID 교육용 EPC global Network 시스템 프로토콜 흐름도
단계 1 : 서버와 리더 동작 시, 리더의 전원구동으로 $\mathrm{TCP} / \mathrm{IP}$ 소켓을 열어(open), 서버와 리더는 알려지지 않은(unwell-known) 포트를 사용 하여 $\mathrm{TCP} / \mathrm{IP}$ 접속한다.

단계 2 : 서버가 리더에 $\mathrm{EPC}$ 태그 데이터를 읽거나 (Read)나 기록(Write)기능을 수행 한다.

단계 $3: \mathrm{EPC}$ 태그 데이터 읽거나(Read)나 기록 (Write)정보를 리더가 수신하면, 리더는 먼저 $\mathrm{EPC}$ 리더와 태그 프로토콜에서 태 그를 선택하려는 Select 명령을 보낸다. 이 후 태그가 리더와 통신가능하면 통신 영역 에 속한다.

단계 4 : 리더가 태그에 Query 명령을 보낸다. 태그는 웅답으로 난수 값(RN:Random Number)을 전달한다.

단계 5 : 리더가 태그로부터 수신된 난수 값이 리더에 저장된 기존의 난수 값과 비교한다. 비교 후 동일하지 않으면 Query Adjust와 Query Reply 명령을 송신하여 같게 되도록 한다.

단계 6 : 리더는 최종적으로 설정된 난수 값을 $\mathrm{ACK}$ 명령으로 전달한 후 $\mathrm{PC}, \mathrm{EPC}, \mathrm{CRCl} 16$ 값을 수신한다.

단계 7 : 리더가 태그를 식별하는 Handle 값을 수신 한 후 태그에 정보를 쓰거나 읽는 Write 또 는 Read 명령을 태그로 송신한다.

단계 8 : 리더가 태그로부터 Write나 Read 명령에 대 한 응답 수신 후 인터넷으로 이 정보를 서버 에 전달한다.

\section{3. 소프트웨어 설계}

본 논문에 소개되는 리더는 $\mathrm{PC}($ 서버 $)$ 와는 인터넷 (TCP/IP기반)으로, 태그와는 $900 \mathrm{MHz}$ 무선으로 접속되 었다. $\mathrm{PC}$ 와 리더는 미들웨어 통신 규약을 준수하며 이 는 명확히 제시되 않아서 통신 규약을 정의하여 처리하 며, 리더와 태그는 EPC global Air Interface 규격[10]을 준수한다. 소프트웨어 설계는 [그림 5]와 같이 리더로부 터 $\mathrm{EPC}$ 태그 데이터 정보의 송, 수신 과정을 처리하는 미들웨어 개발, 리더와 태그간 EPC global Air 
Interface 규격의 적용개발로 나누어 이루어 있다.

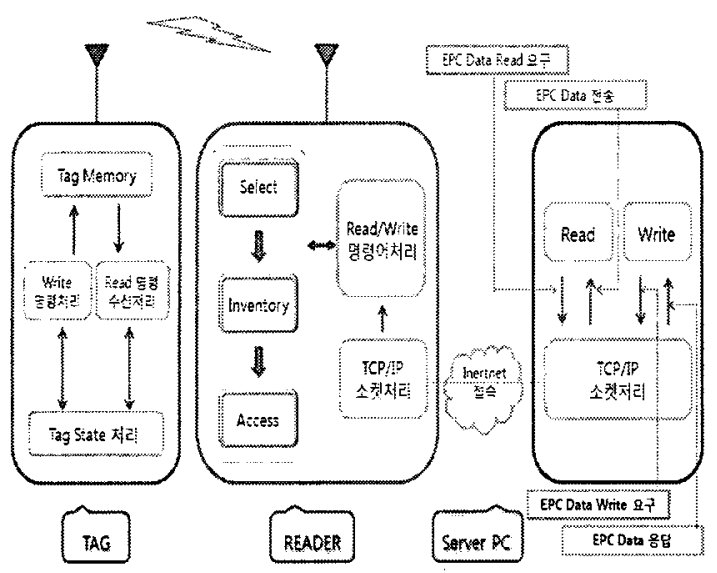

그림 5. 설계 소프트웨어의 구조

미들웨어 개발은 태그 데이터의 이진 정보를 객체로 변환하는 ONS(Object Name Server), 데이터 핸들링을 지원하는 $\mathrm{ALE}, \mathrm{EPCIS}$ 가 있으며, 본 논문에서는 주로 $\mathrm{ONS}$ 을 지원하는 데이터 변화 구조를 적용하였다. 태그 에서 처리되는 $\mathrm{EPC}$ 데이터 종류는 다양하나 96 비트로 구성되는 SGTIN-96(Serialized Global Trade Item Number -96)을 적용하여 개발하였다. 이를 처리하기 위해서는 서버에서 태그에 96 비트로 구성되는 EPC 데 이터의 기록 및 쓰기 기능이 있다. 리더는 서버로부터 태그로 96 비트 $\mathrm{EPC}$ 데이터의 기록 및 쓰기 기능 처리 를 위한 서버와 정보 전달 및 EPC global air interface 규격 처리의 개발이다. 태그 역시 리더와 유사한 $\mathrm{EPC}$ global air interface 규격 처리의 개발이 있다.

$\mathrm{PC}$ 와 리더의 미들웨어 통신 규약 적용 시 다음과 같 이 통신 조건과 명령어/응답 구조를 각각 정의 한다.

정의 $1: \mathrm{PC}$ 와 리더의 미들웨어 통신 규약 적용 시 통신 조건

(1) 명령어는 Read, Write 두개로써 처리한다.

(2) 리더는 TCP Sever, 서버는 TCP Client 로 동작한다.

(3) 리더는 태그 8개를 관리한다.

(4) 리더는 서버가 선택한 태그번호가 1 8로 오면, 그것을 태그의 4 개의 세션 중 $\mathrm{S} 0, \mathrm{~S} 1, \mathrm{~S} 2, \mathrm{~S} 3$ 으로
분류하고 인벤토리 플래그를 A, B 두 개의 상태 로 구분한다.

(5) 서버는 TCP 4000, 리더는 TCP 3000 으로 접속한다. (6) 소켓 접속 후에 명령어 전달한다.

정의 $2: \mathrm{PC}$ 와 리더의 미들웨어 통신 규약 적용 시 명 령어 / 응답 구조

$\mathrm{TCP}$ 접속 후 데이터 필드에 첫 번째 바이트는 명령 어 종류, 두 번째 바이트는 태그번호, 셰 번째 바이트는 4 개로 구성된 태그의 메모리 뺑크를 의미하며, 본 논문 에서는 $0 \times 01$ 로 고정되어 사용되며, $\mathrm{EPC}$ 데이터를 의미 한다.

(1) 첫째 바이트는 태그에 정보를 읽고, 쓰기를 나타내 며, $0 \times 01$ 는 Read, $0 \times 02$ 는 Write 기능 을 의미한다.

(2) 두 번째 바이트는 태그번호로 리더는 임의의 번호 를 지정해 전달한다.

(3) 태그의 EPC 데이터를 읽는 Read Command 기능 의 패킷 구조는 다음과 같다.

. 명령 구조 : 0x01 0x01-0x08 0x01

- 응답 구조 : 0x01 0x01-0x08 0x01 96비트 데이터

(4) 태그의 EPC 데이터 쓰기 Write Command 기능의 패킷 구조는 다음과 같다.

- 명령 구조 : 0x02 0x01-0x08 0x01 96비트 데이터

- 응답 구조 : 0x02 0x01-0x08 0x01

\section{1 서버의 소프트웨어 구조}

본 논문에 소개되는 서버 $(\mathrm{PC})$ 는 리더를 제어하기 위 해 리더와 인터넷( $\mathrm{TCP} / \mathrm{IP}$ 기반)으로 접속된다. 윈도우 $\mathrm{XP}$ 를 운영체제로 하는 서버(PC)의 소프트웨어는 비쥬 얼 $\mathrm{C}++$ 를 사용하여 다이얼로그 베이스로 설계하였다. 서버의 소프트웨어는 EPC global network의 태그 데이 터의 기록 및 읽기 기능을 처리하는 데모 프로그램의 설계와 실습생들이 실습가능 하도록 템플릿 설계로 분 류된다. 개발된 비쥬얼 $\mathrm{C}^{++}$프로그램을 구동하면, 위와 같은 과정을 수행하기 위한 소프트웨어의 처리화면구 조는 [그립 6]과 같은 초기화면을 출력한다. 실습생이 디폴트로 디스플레이되는 EPC global network의 흐름 을 파악하는 Demo 버튼과 직접 프로그램을 코딩하는 
Programming 버튼으로 분류된다. 실습생이 직접 프로 그램을 코딩하는 Programming 부분에서는 코딩 및 컴 파일 완료 후 실행파일을 구동하면, Demo 화면이 출력 되어 태그 테이터 기록 및 읽기 기능을 점검한다.

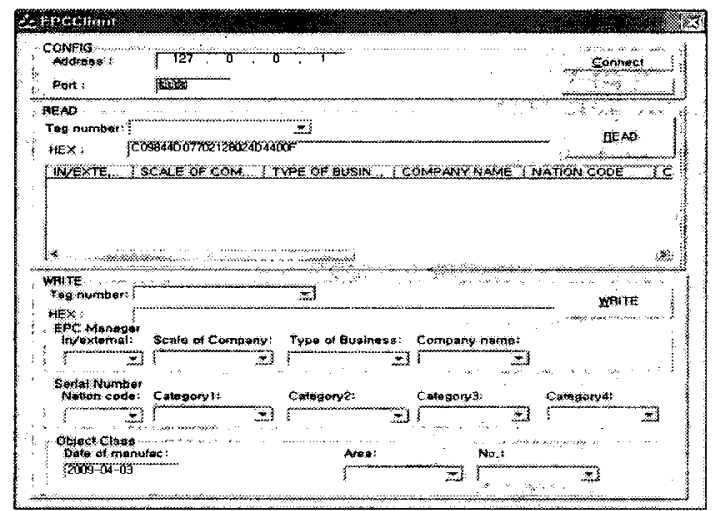

그림 6. EPC_tag_data_Demo 구동 화면

이와 같이 데모기능의 프로그램은 RFID.h는 마크로 변수를 선언하는 헤드파일이고, RFID.cpp는 실제 프로 그래밍 언어이고, RFD.h는 RFID의 실제프로그램의 변수 및 데이터 헤더파일을 구성하는 혜드파일이다. Demo 실습을 구동하기 위한 선행 업무로 리더와 서버 의 TCP 접속이 처리되어야 한다. 리더의 IP주소와 TCP 포트를 입력하여 TCP 접속을 시도한다. Demo 실 습 화면에서는 태그의 메모리에 정보를 기록하는 Write 및 기록된 정보를 확인하는 Read 명령으로 처리 된다. 태그로부터 수신되는 응답을 리더가 Read 명령을 통하여 태그의 정보와 값을 헥사값으로 디스플레이 한 다. Write 명령으로 디스플레이된 핵사값을 입력하여 태그와 리더사이에 정확한 정보전달과정을 확인할 수 있도록 하였다. 이때 Read와 Write 버튼을 실습생들이 누르며, 각각의 처리과정은 다음과 같다.

(1) Read 버튼 처리과정 : 기본적으로 $\mathrm{EPC}$ 태그 데이 터 96 비트를 읽어 와서 이의 정보 출력과정이다. 이의 헥사 값의 출력과 이의 분석으로 Company Prefix, Item Reference, Serial Number로 분류되 며 이의 상세 항목은 다음과 같다. Company Prefix는 회사명, 국·내외회사, 회사규모를 정의하
며, Item Reference는 졔품의 대·중 - 소 분류를 의미한다. Serial Number는 제품 제조 공장 지역, 제조순서, 연월일올 표시한다.

(2) Write 버튼 처리과정 : 기본적으로 EPC 태그 데이 터 96 비트를 태그에 기록한다. 이때 Read 과정과 반대 개념으로 실습생이 Company Prefix, Item Reference, Serial Number로 분류하여 입력하는 방법과 헥사 값으로 직접 입력하는 방법이 있다.

\subsection{1 데모 프로그램의 설계}

$\mathrm{EPC}$ 태그 데이터 기록 및 읽기 기능을 수행할 목적 이므로 중요한 구조는 Read와 Write 버튼 클릭으로 프 로그램이 구동된다. Write 버튼 클릭으로는 실습생이 Company Prefix, Item Reference, Serial Number로 분 류하여 입력하는 방법과 헥사 값으로 직접 입력하도록 구조로 처리된다. 이와 같이 Write 정보 입력후 버튼 클 릭하면 소켓을 구동하여 TCP 접속후 명령 구조 패킷형 태인 명령어 종류:0x02, 태그번호:0x01-0x08, 메모리 벵크:0x01 및 위에서 입력된 Company Prefix, Item Reference, Serial Number값을 가공하여 96비트 EPC 데이터를 생성하여 리더로 전달한다. 이와 함께 토리를 설정하여 실습해야 할 파일명의 함수를 제공한다.

\section{1 .2 템플릿(십습생의 프로그램 코딩부)의 설계}

실습생들을 위한 템플릿 설계는 실제 두 부분으로 구 성되어 진다. 이는 리더와 태그가 정확한 정보를 송·수 신 하는지를 실습할 수 있는 EPC_tag_data_Demo를 모 범 답안으로 이와 같이 프로그래밍하는 기법을 제공한 다. 이때 두 개의 디렉토리 중 리더와 태그 간 RFID $\mathrm{EPC}$ global Data가 정확하게 전달되는지 확인하는 EPC_tag_data_transfer 디렉토리와 EPC 데이터 처리 를 위한 EPC_tag_data processing 부분으로 구성되어 있다.

(1) PC_Demo 부분 : 리더와 태그가 정확한 정보를 송·수신 하는지를 실습할 수 있는지의 실제 프로 그램 구조이며, 다음과 같이 동작한다. 리더와 서 버 $\mathrm{PC}$ 와는 인터넷(TCP/IP)으로 접속된다. 리더 가 전원이 연결되어 있으면 Connect명령을 이용 
하여 리더와 서버는 연결되어 데이터를 송수신 할 수 있으며, 송·수신시 호출되는 형식은 tx(uchar *ptr, uint len), rx(uchar *ptr, uint len) 이며, 이 데이터가 소켓의 TCP 데이터 필드에 엔 캡슐레이션 된다.

(2) EPC_tag_data_transfer 부분 : EPC 태그 데이터 정보의 송, 수신을 위한 함수 작성부를 실습생이 직접 코당하도록 처리한다.

(3) EPC_tag_data_processing 부분 : EPC 태그 데이 터 정보의 수신시 SGTIN-96으로 해독하기 위한 데이터 태이블의 처리 기법을 위한 함수 작성부를 실습생이 직접 코딩하도록 처리한다.

\section{2 리더의 소프트웨어 구조}

미들웨어 기능을 수행하는 서버로부터 수신된 EPC 데이터의 Read/Write 기능 처리를 전달받아 EPC Air Interface 규격[7] 형태의 명령 패킷을 태그로 전달하며, 그에 대해 태그로부터 수신되는 응답 중 $\mathrm{EPC}$ 데이터 Read/Write 기능만 처리 후 $\mathrm{PC}$ 로 전달하는 기능을 수 행하며 구성도는 [그림 7]과 같다. TCP/IP 소켓 접속 후 인터넷으로 접속된 서버로부터 수신되는 명령처리 기능은 Read/Write 명령이다.

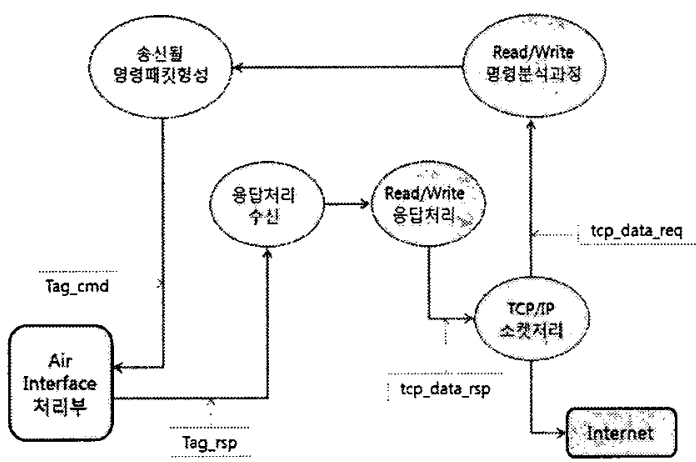

그림 7. 리더의 소프트웨어 구성도

이러한 서버로부터 전달받은 명령 수신 정보를 전달 하는 프리미티브는 tcp_data_req(uc *ptr, int len)이며, 태그로부터 수신되는 응답 중 EPC 데이터 Read/Write 기능만 처리 후 $\mathrm{PC}$ 로 전달하는 기능을 수행하는 기능
의 프리미티브는 tcp_data_rsp(uc *ptr, int len)로 설정 하였다. 명령 수신 후 리더는 태그로 전달하는 정보가 Read명령인지 Write명령 인지를 분석하여 송신될 명령 패킷을 형성하여 태그로 전달한다. 리더에서 태그로 향 하는 명령 프리미티브는 tag_cmd이며 태그에서 처리 된 결과를 리더로 수신되는 프리미티브는 tag_rsp로 설 정하였다. 리더는 태그로부터 수신된 응답 중 $\mathrm{EPC}$ 데 이터 Read/Write 기능만 처리 후 PC로 tcp_data_rsp값 을 전달한다. 본 시스템에서 리더가 다수의 태그와 통 신하기 위하여 안티콜리즌(anticollision)이 가능해야 하 며 안티콜리즌 절차는 리더가 다수의 태그를 액세스하 여 원할하게 통신하기 위하여 사용되게 하였다. 안티콜 리즌 절차를 수행하기 위해 리더는 태그로 Select 패킷 을 전송하며 이때 태그가 리더의 동작 영역 이내에 존 재하는 것들이 응답하게 하기위한 목적으로 설계되었 다. 이때 리더는 한 개 이상의 태그와 통신 시 마스터로 동작한다.

\section{3 능동형 태그의 소프트웨어 구조}

태그는 리더와 EPC global 규격의 RFID 통신을 수행 한다. 태그는 리더로부터 명령어 패킷을 수신하여 처리 후 응답 패킷을 전달하는 기능을 수행한다. 리더로부터 수신되는 명령은 응용 소프트웨어부로 전달되며, 응용 소프트웨어부가 적합한 처리 후 응답 패킷을 리더로 전 달한다. 이들 관계의 구성도는 [그림 8]과 같다.

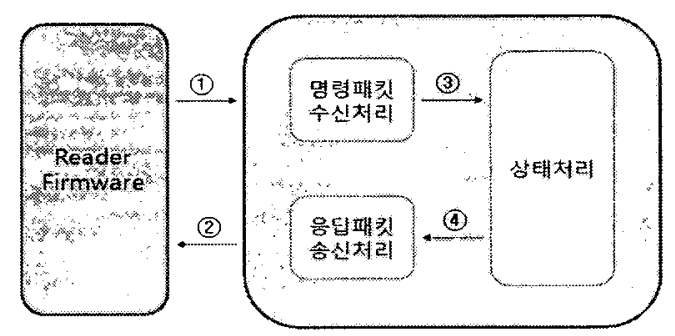

그림 8. 태그의 소프트웨어 구조

[그림 8]에서 리더로 정보를 전달하는 프리미티브는 reader_tx(uc *ptr, int len), 리더로부터 수신되는 프리 미티브는 reader_rx(uc *ptr, int len)이다. 여기서 *ptr 
변수는 메모리에 저장되어 전달될 데이터의 포인터이 고, len은 메모리에서 전달될 데이터의 길이를 바이트 로 표현하는 변수이다. 응용 소프트웨어부의 설계는 리 더로부터 다양한 명령어를 수신하여 상태에 맞게 처리 하는 상태 천이 다이어그램 구조에 따라 동작된다.

태그의 동작과정을 살펴보면 다음과 같다. (1), (2), (3), (4) 은 각 기능 간 시그널 전달을 의미한다. (1), (2)는 리 더와 패킷 송, 수신 시 호출되는 프리미티브로 (1)은 리 더로부터 명령패킷 수신 처리부로 명령패킷이 전달될 때 호출되며 그 형식은 tx(uchar *ptr, uint len)이다. *ptr는 정보를 전달하는 데이터의 시작주소이고, len은 그 정보의 길이이다. (2)는 rx(uchar *ptr, uint len)이며, 응답패킷 송신 처리에서 펌웨어로 응답패킷이 전달될 때 호출된다. (1)에서 명령 패킷 수신 시 그에 대한 소프 트웨어 처리를 수행한 이후 (3)으로 상태 처리를 수행하 도록 한다. 이 후 (4)에서 해당 응답 패킷을 형성하도록 하여 태그가 정상으로 동작하면 해당 응답 패킷을 생성 하여 (2)를 호출한다.

\section{IV. 교육용 RFID 시스템 기능점검}

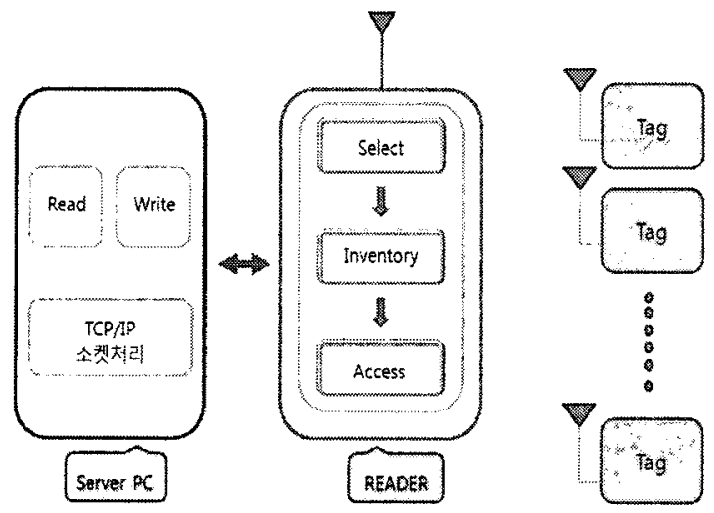

그림 9. 교육용 RFID 시스템의 기능점검

개발된 시스템의 기능 점검은 리더의 소프트웨어가 매우 단순하여 실제 환경에서 추진하였다. 그러나 서버 와 태그는 수행할 기능이 EPC global 규격을 만족하여 야 함으로 매우 복잡하고 난해하다. 따라서 기능점검은
서버와 태그의 동작을 시뮬레이션 하여 버그를 잡아낸 후 실제 환경에서 시험을 추진하였다.

본 논문의 기능 점검은 하나의 리더가 8개의 태그를 관리 하는 환경을 구축하여 리더와 태그는 $5 \mathrm{~m}$ 이상 떨 어져 있고 약 $3 \mathrm{~m} \times 5 \mathrm{~m}$ 정도의 공간에 분산적으로 배치 하여 실험하였다. 시스템의 기능 점검은 [그림 9]와 같 이 서버와 리더, 리더와 태그, 그리고 서버, 리더, 태그 의 연동에 대하여 검증하였다. 서버와 리더의 인터넷 (TCP/IP) 접속을 점검하였다. 리더는 TCP Server로, 서버는 TCP Client로 동작하는지를 점검하였고, 리더 는 서버로부터 태그로 96 비트 $\mathrm{EPC}$ 데이터의 기록 및 쓰기 기능 처리를 위한 서버와 정보 전달 및 $\mathrm{EPC}$ global air interface 규격 처리가 정상적으로 되는지를 점검하였다. $\mathrm{EPC}$ 태그 데이터 96 비트를 정상적으로 읽 고 기록하는지를 점검하기 위해 Company Prefix, Item Reference, Serial Number로 분류하여 표시하는 방법 과 헥사 값으로 직접 표시하는 방법 두 가지 방법으로 정확한 정보전달 되어 표시되는지를 점검하였다. 태그 와 리더의 정상 동작 상태의 점검은 리더의 통신 영역 에 진입하는 태그를 선택하는 Select 과정, 태그와 통신 상태가 되는 Inventory 과정 및 통신 가능한 태그의 메 모리에 정보를 기록 및 읽는 Access 과정으로 분류된 다. Select 과정으로는 Select 패킷을 송신하여 태그를 선택하고, Inventory 과정으로는 Query 패킷, Query Adjust 패킷, Query Response 패킷, ACK 패킷의 송신 과 정상적인 응답으로 통신 가능한 태그의 주소를 구했 다. 마지막으로 Access 과정은 태그에 정보를 기록하는 Write 및 기록된 정보를 확인하는 Read 명령으로 처리 과정을 살펴보았다. 기능 점검 결과는 구현된 RFI 교 육용 시스템에서 리더가 다중 태그 대상으로 성공적으 로 태그 수집을 수행하고 정상적으로 동작한다는 것을 보여 주었고, 서버와 리더는 인터넷(TCP/IP) 접속을 통 하여 $\mathrm{EPC}$ global air interface 규격 처리가 정상적으로 처리되어 $\mathrm{EPC}$ 태그 데이터 96 비트를 정상적으로 읽고 기록함을 보여 주었다. 이와 같이 동작되는 태그 및 리 더의 제작품은 [그림 10]과 같다. 

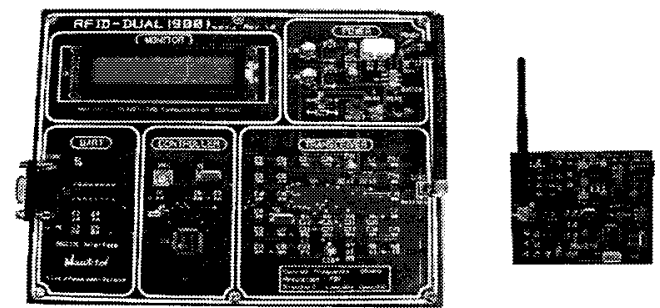

그림 10. 개발한 리더(좌) 및 태그(우) 제작품

\section{V. 결 론}

본 논문에서는 $900 \mathrm{MHz}$ 대역의 $\mathrm{EPC}$ global 표준을 따르고 EPC Air Interface 규격을 만족하는 RFID 교 육용 시스템을 구현하였다. 리더와 태그 사이의 통신을 위해 교육용 환경에서 태그와 접속 가능한 리더의 소프 트웨어 개발을 임베디드 환경에서 구성하였고, 리더에 접속되어 이를 제어하는 $\mathrm{PC}$ 소프트웨어 개발을 윈도우 환경에서 비쥬얼 $\mathrm{C}++$ 언어를 사용하여 구현하였다. 하 드웨어 개발환경으로는 리더와 태그는 ATmegal28을 프로세서로, 디버거 환경은 AVR 컴파일러를, 개발언어 는 $\mathrm{C}$ 언어를 활용하였다. 이의 기능 점검을 위하여 서 버와 리더의 인터넷(TCP/IP) 접속을 점검하고, 서버와 리더, 리더와 태그, 그리고 서버, 리더, 태그의 연동에 대하여 검증하였다. 리더와 서버 PC간에 RS-232-C 접속을 통하여 리더를 제어하였던 것을 미들웨어 개념 의 인터닛 $(\mathrm{TCP} / \mathrm{IP})$ 접속을 통해 리더를 제어하도록 개 선하였으며, EPC 코드중 하나인 SGTIN-96을 적용하 여 구현되어 앞으로 개별 물품 식별 $\mathrm{RFID}$ 시장의 활성 화를 대비하기 위한 기술 교육용 장비로 활용될 수 있 도록 하였다. 또한 $\mathrm{EPC}$ 태그 데이터 정보의 송수신을 위한 함수 작성과 $\mathrm{EPC}$ 태그 데이터 정보의 수신시 SGTIN-96으로 해독하기 위한 데이터 테이블의 처리 기법 프로그래밍 실습을 할 수 있는 기능을 구현하여 이를 통해 능동형 $\mathrm{RFID}$ 시스템의 실제 환경 적용기술 교육과, 임베디드 프로그래밍 교육에 많이 활용할 수 있올 것으로 보인다.

향후 연구 과제로는 본 논문에서는 $\mathrm{EPC}$ 코드의 종류 는 다양하나 96비트로만 구성되는 SGTIN-96을 적용
하여 시스템을 구현하였지만 앞으로 EPC global 규격 에 적합한 $\mathrm{GD}, \mathrm{GRAI}, \mathrm{SGLN}, \mathrm{SSCC}, \mathrm{SGTIN}$ 의 64 비 트, 96비트, 256비트로 구성되는 코드가 적용되는 시스 템의 개발에 관한 연구가 필요하다. 이와 함께 본 논문 에서는 주로 ONS(Object Name Server)를 지원하는 데 이터 변화구조가 적용된 미들웨어 환경을 사용하였지 만, 앞으로 RFID 태그를 인식한 리더가 애플리케이선 계층으로 데이터를 전달하는 역할을 하는 $\mathrm{ALE}$ (Application Level Event), $\mathrm{EPC}$ 와 관련된 정보에 접근하기 위한 표준인터페이스를 위한 규격인 $\mathrm{EPCIS}$ (EPC Information Service)와 같은 여러 미들웨 어 환경에 맞는 교육용 시스템의 개발에 관한 연구가 이루어져야 한다.

\section{㧒}

[1] Simon Grafinkel, "RFID Applications, Security, and Privacy," Addison Wesley, 2006.

[2] 정중수, "능동형 태그를 포함한 $900 \mathrm{MHz} \mathrm{RFID}$ 교 육용 시스템의 설계", 한국인터넷정보학회논문지, 제8권, 제4호, pp.51-59, 2007.

[3] IDTechEx, "Item Level RFID 2008-2018, Technology, Standards," 2008.

[4] 최길영, 성낙선, 모희숙, 박찬원 권성호, "RFID 기 술 및 표준화 동향”, 전자통신동향분석, 제22권 제 3호, 2007.

[5] EPC global, http://www.epcglobalinc.org

[6] Alien, http://www.alientechnology.com/readers/ index.php

[7] AWID, http://www.awid.com, "MPR-3014 EPC Gen2 RFID Reader"

[8] http://www.hybus.net/sub02/producthtm?c_par ent $=133$

[9] Alien, http://www.alientechnology.com/tags /index.php

[10] EPCglobal, "The EPCglobal Architecture Framework EPCglobal Final Version 1," 2005. 
[11] 차재룡, 김재현, "RFD 시스템에서 EPCglobal Generation 2 프로토콜의 성능 평가", 한국통신학 회 논문집, 2006.

[12] ETRI, "900MHz 대역 수동형 RFID 리더 구조 설계서”, 한국전자통신연구원, 2004.

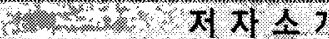

김 대 희(Dae-Hee $\mathrm{Kim})$

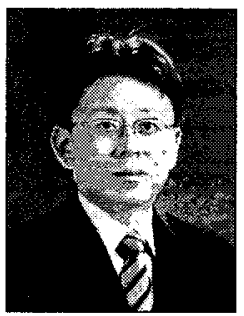

- 1999년 2월 : 한국방송통신대학 교 컴퓨터과학과(학사)

- 2002년 2월 : 안동대학교 공학대 학 컴퓨터공학과(공학석사)

- 2005년 2월 : 안동대학교 공과대 학 전자정보산업학부 정보통신

공학과(박사수료)

<관심분야> : 유비쿼터스네트워크, 데이터네트워크, 능동형 $\mathrm{RFD}$ 시스템

\section{정 중 수(Joong-Soo Chung)}

정회원

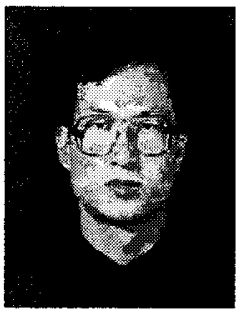

- 1981년 2월 : 영남대학교 전자공 학과(학사)

- 1983년 2월 : 연세대학교 전자공 학과(공학석사)

- 1993년 2월 : 연세대학교 전자공 학과(공학박사)

- 1983년 3월 1994년 2월 : ETRI 연구원, 선임연구원

- 1987년 8월 1989년 8월 : 벨지움 Alcal / Bell Tele-phone사 객원연구원

- 2000년 1월 2001년 1월 : 미국 UMASS/Lowell 전 산학과 객원교수

- 1994년 3월 현재 : 안동대학교 공과대학 전자정보 산업학부 정보통신공학과 교수

<관심분야> : 데이터네트워크
김 휴 찬(Hyu-Chan. Kim)

정회원

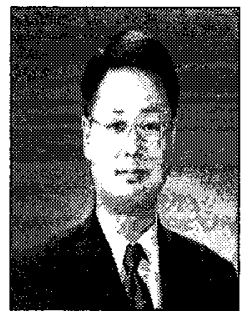

- 1993년 2월 : 제주대학교 에너지 공학과(학사)

- 1997년 2월 : 제주대학교 에너지 공학과(공학석사)

- 2002년 2월 : 제주대학교대학원 컴퓨터공학과(박사수료)

- 1999년 현재 : 제주한라대학 전자상거래과 교수 <관심분야> : $\mathrm{RFD}$ 응용, $\mathrm{e}^{-}$비즈니스모델, 최적화

정 광 욱(Kwang-Wook Jung)

정회원

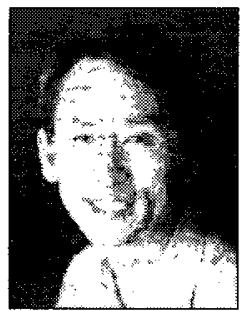

- 1982년 2월 : 경북대학교 전자공 학과(학사)

- 1984년 2월 : 경북대학교 전자공 학과(공학석사)

- 1984년 3월 1992년 2월 : 삼성 전자 근무

- 1996년 8월 : 경북대학교 전자공학과 (공학박사)

- 1992년 3월 현재 : 구미1대학 정보통신공학과 부 교수

- 2000년 7월 - 현재 : (주)맨엔텔 대표이사

<관심분야> : 무선통신기기, 컴퓨터네트워크

김 석 규(Seog-Gyu Kim)

정회원

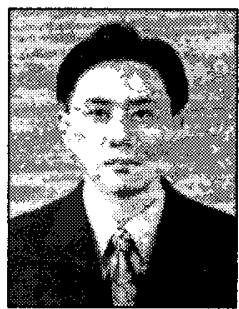

- 1990년 2월 : 연세대학교 전자공 학과(학사)

- 1992년 8월 : 연세대학교 전자공 학과(공학석사)

- 1997년 8월 : 연세대학교 전자공 학과(공학박사)

- 1997년 10월 2004년 3월 : SK텔레콤 선임연구원

- 2004년 3월 2006년 3월 : 연세대학교 전기전자공 학부 연구교수

- 2006년 4월 현재 : 안동대학교 공과대학 전자정보 산업학부 정보통신공학과 교수

<관심분야> : 센서네트워크, 차세대네트워크 